\title{
Loving the alien
}

\author{
Plants are different and amazingly diverse. We should not be embarrassed to study them independently of their
}

many uses.

$\mathrm{t}$ seems almost de rigueur these days

for grant proposals and publications to

end with a promise that their research will translate into applications destined to make human life better in some way. Even as remote possibilities, these promises of societal benefit are so common as to have become worthless; conventional hooks to catch the attention of readers or funders. We will produce more food in less space; keep yields high even in sub-optimal conditions; use our discoveries to produce more wood, fibre, chemicals, drugs, energy and so forth. This final mention of often tenuous economic applications is so much the norm that we frequently only notice it on the rare occasion that it is absent.

This is not to deny that much research in plant biology does have these direct or at least plausible applications, but the constant repetition of the mantra of 'practical applicability' can make it seem that the main goal, indeed the only goal, of plant sciences is discovering ever more effective ways to force nature to give us what we want. As if plant biology was more concerned with humanity than with the plants themselves.

Direct short-term agricultural applications are of course a noble and important goal (and Norman Borlaug is a rightly revered figurehead for such agriculture-focussed plant sciences), but fundamental research for the sake of pure knowledge has its own merits, and should never be dismissed as an unprofitable intellectual exercise. Curiosity and a certain sense of wonder for a fascinating and extremely complex living world is probably the real motivation for many researchers, and the basis of their academic pursuits. Is there anything more satisfying and enlightening to understand how a flower is made, how lateral roots grow, how a symbiotic relationship between fungi and trees develop, what the use of trichomes is, how rice became domesticated, how a plant can perceive its neighbours?

This is exactly the motivation behind 'Fascination of Plants Day' organised under the umbrella of the European Plant Science Organization, a currently biannual event on 18 May. The celebration of all things 'planty' has grown considerably from its inception in 2012. This year, the 5th Fascination of Plants Day saw over 800 events take place in 51 countries worldwide. Hopefully, by the time 18 May 2021 comes around, the events will number over 1,000 .

Of course, understanding plants better will lead to practical applications with potentially world changing benefits, a fact not lost on researchers - although a Review in this issue of Nature Plants discusses the challenges of actually delivering on such promises. But is it why we do research? Plants' alterity is intellectually exciting and fascinating; their fundamental otherness should be quite enough to capture our curiosity. There is no need to look for aliens in science fiction books, as they are already here around us; and while frequently not 'little', and never 'men', they are green most of the time.

Plants are much older than humans, and followed a radically different evolutionary path. They conquered land before vertebrates, and show immense diversity in shape, adaptation and way of life. For example, Arenaria bryophylla can live and reproduce at altitudes over 6,000 meters above sea level, an impossible feat for humans. Mangrove trees grow in sea water. Cacti and other desert plants survive in extremely arid landscapes through various ingenious adaptations. Other plants prefer the semi-obscurity of cave entrances. In our cities (possibly the most hostile of environments for non-humans), we have all seen self-seeded adventurers, including Arabidopsis thaliana, living and reproducing in tiny cracks in the pavement, containing maybe a teaspoon of organic matter at most.

Phytodiversity is not only geographical and environmental. The timescale of plant life is different from ours and necessitates a mental adaptation. They move, mostly through growth, but very slowly, rarely detectable by the human eye. Trees can live for many thousands of years whilst some seeds, at the first hint of rain, develop and reproduce in only a few weeks to give us magnificent, sudden and ephemeral desert blooms.

Plant development is radically different from that of animals. They grow new organs throughout their life and transform themselves to satisfy their changing needs. Not enough light? Just elongate to emerge from the canopy. Not enough water or nutrients? Grow more roots! An animal ate my apex? Grow two more in its place. Unlike boringly symmetrical animals, plants have a multitude of shapes, often gracefully balanced like an upside-down mobile by Alexander Calder. To approach and study plants, one needs a fundamental change to their point of view, a completely different frame of mind.

We should love plants for themselves, for what their secret relationships can teach us about the multiplicity of ways to live on our planet. We should be curious and excited about them first, without thinking of what they can give us in return. The food and oxygen plants produce are utterly indispensable to us, but plants are a subject of intellectual interest not just because they are useful, they command a deeper level of appreciation. We do not love plants because they feed us; neither does reading a novel or listening to music. Art and beauty are useless in practical terms, and yet so necessary for our wellbeing.

Recently there have been much discussions of 'plant blindness', a bias that prevents human beings from noticing the plants surrounding us; we evolved instead to focus on the immediate dangers posed by crawling insects or big mammals. Perhaps plant biologists can suffer from a different kind of blindness, unable to see beyond an obsessive focus on the practical utility of what we do, to the amazing beauty and diversity of the plant world.

Studying plants is a journey into a different world far from our animal-centric perspective. It helps us understand complex relationships that exist in nature, and it prepares our minds for other convoluted interaction networks, whether they are biological, ecological, human or political. Plant sciences teach us to accept the amazingly elaborate world in which we live, where a few universal physical rules and a shared genetic background created such a variety of living organisms on this small piece of rock floating through space.

We must protect, love and study plants because they are magnificent and captivating products of evolution. So, if only for a moment, forget about yields and embrace plant science as a portal to a world of fascination.

Published online: 10 June 2019 https://doi.org/10.1038/s41477-019-0463-3 